\title{
Interfaces
}

\section{The Synaesthetic Experience of Light: Francis Bruguière's Abstract Photographs}

\section{Kristen A. Adlhoch}

\section{(2) OpenEdition \\ 1 Journals}

\section{Electronic version}

URL: http://journals.openedition.org/interfaces/232

DOI: 10.4000/interfaces.232

ISSN: 2647-6754

\section{Publisher:}

Université de Bourgogne, Université de Paris, College of the Holy Cross

\section{Printed version}

Date of publication: 1 January 2015

Number of pages: $75-93$

ISBN: 9780983175247

ISSN: $1164-6225$

\section{Electronic reference}

Kristen A. Adlhoch, "The Synaesthetic Experience of Light: Francis Bruguière's Abstract Photographs", Interfaces [Online], 36 | 2015, Online since 01 January 2018, connection on 07 January 2021. URL: http://journals.openedition.org/interfaces/232 ; DOl: https://doi.org/10.4000/interfaces.232

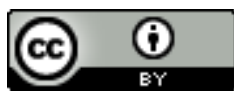

Les contenus de la revue Interfaces sont mis à disposition selon les termes de la Licence Creative Commons Attribution 4.0 International. 


\title{
THE SYNAESTHETIC EXPERIENCE OF LIGHT: FRANCIS BRUGUIÈRE'S ABSTRACT PHOTOGRAPHS
}

\author{
Kristen A. Adlhoch
}

\section{Introduction}

Photography is never a wholly visual medium, despite established cultural conventions and theoretical frameworks that emphasise the opposite. From its earliest days, practitioners and critics pointed to the way in which photography documents, democratically and with fidelity, all that is placed before the camera's lens, while modernist photographers of the early-twentieth century such as Paul Strand heralded photography's "absolute unqualified objectivity" (136), renouncing the painterly style of Pictorialists and eschewing manipulations of any sort in favour of the objective, "straight" print. Presented with a history that is so rooted in the truthful representation of the visible world, it is hardly surprising that photography is associated almost exclusively with sight and visuality. Yet closer examination of photography practice and theory between the First and Second World Wars demonstrates that the concepts of verisimilitude, objectivity and the purity of optics were under scrutiny by many avant-garde photographers of the time. Moreover, debunking the existence of purely "visual media" is an increasingly predominant theme in the scholarship of contemporary art history and cultural studies (Mitchell; Di Bell and Koureas). It is from this vantage point of historical re-evaluation and attentiveness to the non-visual attributes of the photographic medium that I scrutinise the relationship between synaesthetic experience, intermedial experimentation, and abstract photography practice of the 1920 s.

In this paper, I argue that abstract photographs in the early-twentieth century frequently relied heavily on senses other than sight in their creation and reception, which triggered multi-sensory and emotional responses in their viewers. Moreover, photographers and other artists who were engaged in this type of image making were typically drawing influences from other forms of creative production, thus breaching, interrogating and redefining the boundaries of the medium and positioning photography as a fluid and intermedial means of expression rather than one that was rigidly defined by its visuality, with a static and unchanging essentialised nature. Consequently, in this discussion, intermedia and synaesthesia are deeply intertwined in both their theoretical conceptions and material manifestations, providing a productive alternative framework from which a new discourse of abstract photography can be developed. In my analysis, these two modalities are coupled with a third crucial element: the use of 
light as a tangible, plastic medium in the creation of abstract photographs. Thus, my analysis privileges intermedia as a mode of production, synaesthesia as a mode of experience, and light as the primary creative element of their production. This argument is augmented by primary source materials, which corroborate the existence of a multi-faceted dialogue regarding the creation and meaning of abstract photographs in this era.

Before proceeding, certain qualifications are required regarding my terminology. The term synaesthesia refers to the condition in which a sensory impression is stimulated through one sense but experienced through another - for example, "coloured hearing" and "visual music." Current research in the field of synaesthesia and the arts tends to fall under two categories: on the one hand are neurological studies that explore synaesthesia through scientific methodologies in order to obtain empirical proof of the phenomenon (Baron-Cohen and Harrison; Cytowic); and on the other hand are studies that fall under the rubric of art history and visual culture that emphasise attempts to represent the experience of synaesthesia through artistic means (Brougher et al; Zilczer). The association of synaesthetic experience with artists, writers and composers gained prevalence in the mid-nineteenth century and peaked around 1930 before experiencing a decline in interest that has only recently been reversed (Cytowic 20). In the following discussion, synaesthesia is considered as a mode of perception in which one sense perception stimulates or otherwise suggests another sensorial experience. Such a classification exists alongside but independent of studies that privilege either empirical proof of neurological synaesthesia, or an artist's intent to create a transcendent synaesthetic experience through emulating the formal qualities of another medium, such as music. However, Baron-Cohen and Harrison argue that the condition of "neurological" or "developmental" synaesthesia - that is, an involuntary condition that occurs as a result of biological determinants - requires the use of objective neurological tests for diagnosis, and hence is nearly impossible to confirm in historical cases (11). In their opinion, discussions of the existence of synaesthetia in artists of the past are in fact frequently relying on "pseudo-synaesthesia," in which the condition is the result of metaphor or the learned association between different perceptual experiences (8-12).

My aim is not to apply a specific model of synaesthesia to any of the artists or theorists that I discuss. Rather, I am interested in the notion that abstract photographs, amongst other artistic media, can provide a different mode of sensory experience by overcoming the emphasis on visuality that has traditionally been applied to it. This approach involves repositioning the consumer of abstract photographs as an embodied participant in the artistic experience, as opposed to a "viewer" for whom sight is the only means of engagement. In the interwar era, many artists were engaged in a discourse surrounding the use of light as a creative medium, a dialogue which often borrowed from or was influenced by the use of light in differing forms and media. The notion that photography could transpose 
visual imagery into different sensual experiences plays an important role in this discussion. Additionally, the synaesthetic effects that accompany the concept of light as a tangible medium demonstrate that it is one that is particularly rooted in our sense of touch.

Many contemporary discussions about abstract photography that rely on such theories have found purchase in contemporary scholarship in which the alleged inherent formal qualities of the medium are privileged over their contingent elements, reinforcing a traditional and outdated photography canon (Jäger; Rexer). By contrast, my interpretation of the term "abstract photography" follows a path suggested by Matthew Witkovsky in which the material embodiment of the photograph in question is treated with equal weight to its formal aesthetic characteristics (215). In this conception, the photograph's materiality is not defined merely by its own physical manifestation, but also includes the cultural, social and economic uses of the photograph, the physical presences of both the artist and viewer, and the varied interpretations that might be applied to it over time. Thus, the surface image of a photograph comprises only one facet of abstraction, which is enriched and expanded by the underlying theories, impulses and influences that impelled such creations. I propose that abstract photographs of the early-twentieth century are defined in the attempt by the photographer to renegotiate the terms of the medium itself by challenging the truth claims and alleged transparency of photography. Furthermore, in focusing my analysis on artists who were engaged with using light as their primary means of expression, I am distinguishing a subset of artists who are not limited to the medium of photography, but, on the contrary, who are present as well in such varied modes of production as cinema, theatre, literature, painting, dance, and other works that are positioned in the interstices of these modes of expression.

\section{Primary Source Materials}

In support of this argument, I rely on numerous primary sources, both in the form of artworks that manifest the convergence of synaesthesia, intermediality, and light, as well as texts of criticism and theory that demonstrate the contemporaneous interest in these models. I make particular reference to abstract photographs made by Francis Bruguière (American, 1879-1945), particularly those used in his collaboration with Lance Sieveking (British, 1896-1972), on a book titled Beyond This Point (1929) [Fig. 1]. The scenario of Beyond This Point, written by Sieveking, traces the varied potential responses to a series of three different crises that might befall the modern man. Sieveking's literary style subverts many of the conventions associated with traditional dramatic structure such as linear time and third-person narrative. The text is interspersed with - and literally interrupted by - abstract 


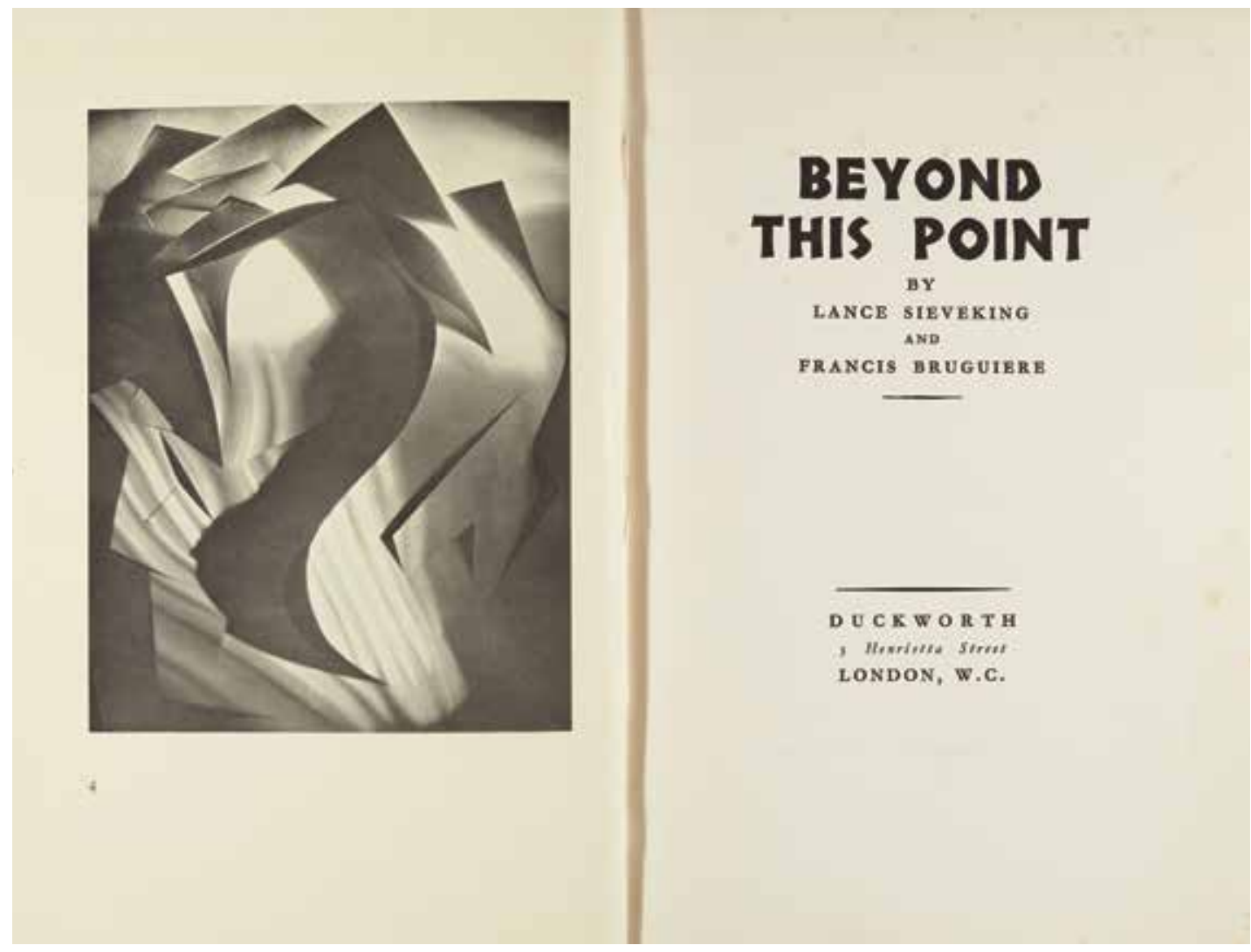

Fig. 1: Francis Bruguière and Lance Sieveking, "Title Page," Beyond This Point (London: Duckworth, 1929). Courtesy of the University of St Andrews Library Special Collections (Photo PR6037.I48F29 — pgs. 4-5). 
and multiple-exposure photographs made by Bruguière. Whilst the underlying theme of the book is the human pursuit of emotional and existential coherence, with the potential to lead the reader to an apogee "beyond this point" (9-10), the formal objective of Beyond This Point is to disrupt the traditional illustrative relationship between text and image, as is explicitly stated in a note just following the colophon: "This book is an example of absolute collaboration. The text, which has been written by Sieveking, is inseparable from the photographs, which have been designed by Bruguière. In each section of the book, the photograph and the text are integral parts of each other," (n. p.). Beyond This Point demonstrates the intentional conflation of synaesthetic experience, intermedial practice and the creative potential of light. By playing with the temporal arc of the storyline and subverting the narrative and stylistic conventions of prose and photography, Sieveking and Bruguière experimented with the non-mimetic possibilities of their chosen media, and ultimately attempted to embody the psychological traumas inflicted on the human psyche by the modern world through literal and non-figurative means.

Other examples of primary source material provide evidence that synaesthesia and intermediality are not merely contemporary paradigms applied in retrospect in a teleological fashion. Rather, these were in fact contemporaneous frameworks that were being explored by various artists and critics in the period between the wars. Articles by two contemporaneous theorists, László Moholy-Nagy (Hungarian, 1895-1946), and Harry Alan Potamkin (American, 1900-33) furnish coeval models in the discussion of Beyond This Point and abstract photography. As a theorist and teacher, Moholy wrote extensively and passionately about the possibilities latent in new technologies such as photography and film, and was particularly interested in the use of light as a plastic medium and the perceptual, sensuous, and aesthetic implications of such artworks. Although Moholy and Bruguière were not in direct dialogue, they would have been aware of one another's work and were situated within a broader conglomeration of "new vision" artists exploring the non-objective potential of photography. Through his photograms, photographs, "photoplastics," films, and kinetic sculptures, Moholy put into practice the theories that he advocated. A more in-depth discussion of synaesthesia, intermedia and light would certainly include examples of Moholy's art as well as an engagement with his theories, but is unfortunately beyond the scope of this discussion.

Potamkin was a poet, educator, and Marxist film critic who wrote extensively about film theory between 1927 and his untimely death in 1933. Through his work as the American correspondent for Close Up, the British avant-garde "little magazine" of film, Potamkin was introduced to Bruguière's work, and was in direct dialogue with the artist about his experiments in abstract photography, and his plans to pursue them into the cinematic medium as well ("Phases of Cinema Unity: II" 22). In utilising 
these sources, I wish to foreground the fact that concurrent models for analysis existed alongside the artworks that I am studying, and moreover, that while these theorists may have lacked the terminology and contextual frameworks that we rely on today, their theories are nonetheless capable of shedding light on both the works themselves, and the socio-cultural circumstances of their creation.

\section{Intermedia: Art "Compounded"}

The term "intermedia" was adopted by the Fluxus art collective in the 1960s as a way to describe artworks positioned between the discrete borders that define established media, and "not intended to conform to the pure medium" (Higgins 49). Intermedial artworks lack the social and artistic codes that regulate the production and interpretation of such objects, and, crucially, are conceived in opposition to notions of medium purity and essentialism. In challenging the codified and entrenched formal, critical and aesthetic attributes of a medium, intermedial creations also subvert their anticipated sensory experiences. Thus, intermedia and synaesthesia share an intrinsic connection, and, in certain cases, an absolute reliance on one another: just as synaesthesia transgresses perceptual boundaries by transposing the experience of sensate stimuli, intermedia blurs the divisions between artistic modes of communication. Intermediality is not an entrenched paradigm, but must rather be understood as a mutable framework of shifting variables based on a complex relationship between the producer, viewer and the mediums employed.

Although the expression "intermedia" was not in common usage in the era between the wars, the ethos of intermedial creation was prevalent amongst the avant-garde during this time. Cinema represents one site of sustained experimentation in both production and theory that embraced the possibilities offered by a cross-medium approach, and is particularly germane to the discourse of both Bruguière's abstract photographs and Beyond This Point. Film theory, critique, and production flourished in the first three decades of the twentieth century, propelled by the expanding commercial film industry on the one hand, and a conglomeration of productive art film communities on the other. By the 1920s, commercial films had achieved dominance in imposing the artistic conventions and popular consumption of the medium. A vociferous counterculture of avant-garde film communities arose in opposition, and while they tended to be highly regionalised, they were also incredibly well networked through film societies and modernist "little magazines" dedicated to the art of film. The theories and criticism disseminated through these channels challenged the norms of commercial filmmaking, actively working to distance film from its commonly perceived atavistic link to the theatre, and to reverse the trend towards traditional narrative structures. 
Intermediality was a key tenet of film theory in the late-1920s, found in the guise of terms such as "compounded" or "synthesised" cinema, during the period when the silent film model was being overtaken by sound film or "talkies." Potamkin, for example, articulated a theory of the "compound cinema," in which all the formal elements of the film - including features such as sound, colour, texture, and two- and three-dimensionality - achieve unity through rhythm, thus transcending the experience of the merely aggregated components (Potamkin, "Compound Cinema" 6-7). For Potamkin, each compound represented a different form of cinema, leading to a wide variety of potential cinematic configurations. Each of these compounds was valid, in Potamkin's view, as long as they respected the intrinsic characteristics of the film's structure through a balance of formal elements. For example, Potamkin advocated a new "optophonic" form of sound film, in which the optical and aural components form a counterpoint, but rejected films that simply appended "imitated speech" to "flat silent film" ("Compound Cinema" 5-6). The act of compounding is based on the notion that film is not an essentially visual medium, and this is another recurring theme in Potamkin's writing ("Phases of Cinema Unity: III" 31). Rather, he refers to film's effects as "visual-motor": "The authentic perception of movement, to quote Jaques-Dalcroze, is not the visual order, but of the muscular order" ("Phases of Cinema Unity: III” 32). Potamkin's reference is to Émil Jaques-Dalcroze (Austrian, 1865-1950), who originated the "eurythmics" method of music education, in which the physical and kinaesthetic responses to auditory stimulation are given precedence over the abstracted visual notations of written musical scores. The implication is that film is registered kinaesthetically as well as visually, a subversion of our anticipated engagement with the medium that makes possible a literally embodied experience.

There is already a precedence of considering the filmic attributes of Beyond This Point. In a contemporary analysis of the book, Anne McCauley persuasively argues that the visual disruption caused by Bruguière's photographs is akin to the "caesuras and optical rests" (60) often found within modernist cinema, and which Potamkin discussed in various different articles (e.g., "Phases of Cinema Unity: I" 18). Moreover, Potamkin himself originally noted the filmic qualities of the book, in an article written in 1930 titled "Tendencies in the Cinema." Referencing both his own theory of the compound cinema, as well as the "cinematic" literary style of James Joyce, Potamkin wrote: "What is the Joycean method if not a desire for the compound? Lance Sieveking, writer, and Francis Bruguière, photographer, have endeavoured to compound the photograph with the word. These are aspirations against the medium and towards another form, the cinema" (43). Potamkin's implication is not that the authors have created a new type of text or photograph, but rather that text and image have "compounded" to take on a wholly different, cinematic form. Potamkin's assessment was likely influenced by Sergei Eisenstein's theories of film form and montage, with which Potamkin was well acquainted. In his essay 
"A Dialectic Approach to Film Form", Eisenstein asserted that "dynamic effects" can be created in still media such as paintings, poetry, and ideograms when the elements "collide," allowing the eye to retain a visual impression that creates the sensation of movement (49-50). The dramatic and cinematic effect of montage is thus not effected sequentially, through images placed side by side, but instead through the spatial-temporal structure of superimposition. In Beyond This Point, the photographs literally interrupt the text mid-sentence, and the narrative then picks up after the image at a different point in the narrative [Figs. 3-5]. Text and image are placed in close proximity on the same page, implying that they are meant to be experienced simultaneously.

The potential for synaesthetic experience is revealed when the traditional literary framework is removed, and the intermedial characteristics of film are applied to Beyond This Point. This shift depends on rethinking the experience of reading a book or looking at a photograph as independent and wholly separate events, even if executed in close proximity. Instead, I believe that one is intended to experience both visual and literal transmissions concurrently. In their placement within the text midsentence, the photographs create a collision between the literal and visual components of the book. The reader's internal vocalisation of the words is ceased without warning, and their relationship to the book suddenly changes from that of a reader to that of a viewer. The reader/viewer thus simultaneously retains the literal and visual elements of the book, synthesising them into a new perceptual experience.

\section{Light: "A new medium of expression"}

"The principal difference between what we might term the old photography and the new photography is that the old sought to give significance to form by means of light, whilst the new seeks to give significance to light by means of form" (Mercurius 39). The implication of this sentiment which was expressed in an article about Bruguière's photography written by his friend and sometimecollaborator Oswell Blakeston (under the pseudonym Mercurius) — is that light itself had replaced concrete objects in and of the world as the subject matter of the "new photography." This conception of light as a plastic, creative medium, was not restricted to photography: in the early-twentieth century, many artists were exploring the creative and plastic potential of light, through various different media. Unlike painting or sculpture, for instance, there were no established conventions for the creation of "light art", rendering it both deeply intermedial and capable of stimulating synaesthetic responses. The list of practitioners working creatively with light at this time reveals the diversity of the practice, including, but not limited to: the illuminated serpentine dances of Loïe Fuller; early experiments in abstract cinema by Futurists Arnaldo Ginna and Bruno Corra; and a considerable interest in "light 
music," beginning with Alexander Rimington (c. 1895) and burgeoning in the first part of the twentieth century in the work of Alexander Scriabin, Thomas Wilfred, and countless other practitioners.

There is a direct lineage between the abstract light-based photographs that Bruguière began making around 1922, and the burgeoning interest in light music subsequent to World War One. His impetus, it would seem, was a photographic assignment that he undertook for Theatre Arts Monthly, documenting a performance of Thomas Wilfred's "clavilux" light-organ prior to its debut in New York. Wilfred's light art, which he called "lumia," merged a musical structure with colour theory, in which a light "score" was played on a clavier that in turn engaged a series of powerful light sources, lenses, and coloured filters to create a temporal, chromatic, and typically abstract light performance (Stein 10). For Wilfred, light was the medium to which modern artists were turning: "More and more artists of our generation have begun to contemplate light with the eyes of a sculptor gazing upon a block of marble — seeing in light a new and basic medium of expression with unlimited possibilities" (qtd. in Stein 8). Having met Wilfred and experienced lumia, Bruguière began to experiment with abstract photographs in which the primary subject matter was light mediated in different ways. He employed two different techniques for their creation: the first method involved moving a light source or sources in front of the open lens of his camera over a long duration or through multiple exposures, a series which he called "Designs in Abstract Forms of Light" [Fig. 2]. The other series, commonly referred to as "Cut-Paper Abstractions," [Fig. 1] was created by carving lines into sheets of paper to create abstract forms, which Bruguière then lit with different and variously transposed light sources over an extended duration.

While Bruguière's direct interest in light art seemingly stemmed from a personal experience with lumia, light also played a critical role in his professional work as a photographer in the modernist New York-based "New Stagecraft" theatre community between 1919-1927. Bruguière's professional success hinged on his exceptional aptitude for photographing theatre lighting as the stage designer wanted it to be experienced by the theatre-goer. In order to recreate the aesthetic intent of a particular set design, Bruguière had to merge technical skill with artistic vision, a complex procedure which entailed representing the different spectral lengths of the variously-coloured theatre lights in a black and white photograph. Bruguière utilised a stationary camera and a long exposure time, during which he manipulated the stage lights in order to render the designer's artistic vision of an entire stage set into a still photograph in a process that did, indeed, closely resemble his method of creating abstract designs (Bruguière 401). Bruguière's photographs of stage settings, dramatic tableaux, and costumes were hailed by stage designers for their beauty, artistry and technical precision, and he garnered a reputation as "One of the first artist-photographers of the theatre" (Gilder et al 673). 


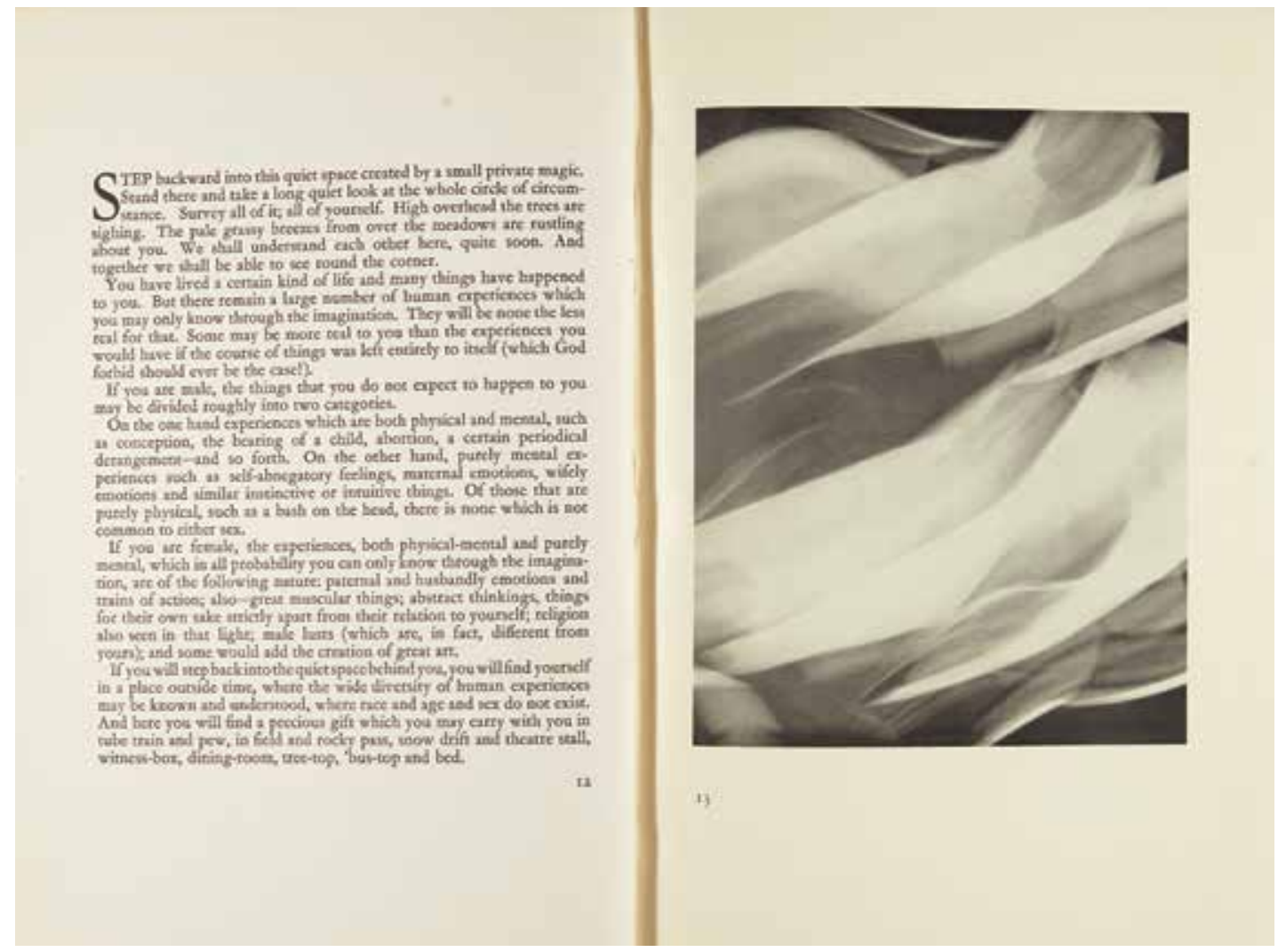

Fig. 2: Francis Bruguière and Lance Sieveking, "Section A. Humanity: Up He Goes. Attitudes towards the near approach of death." Beyond This Point (London: Duckworth, 1929). Courtesy of the University of St Andrews Library Special Collections (Photo PR6037.I48F29 - pgs. 12-13). 
Bruguière's comprehension of theatre lighting was almost certainly influenced by the theories of the Swiss set designer Adolphe Appia (1862-1928), whose notions about the concrete properties and sensuous potential of light were assimilated by the New Stagecraft designers. Appia conceived of light as a concrete element of the stage that must replace the illusionistic painted backdrop in order to "give life" to the actor and the three-dimensional space of the stage ("Actor" 114). Following Wagner's notion of Gesamtkunstwerk ("the total work of art"), Appia believed the future of stage production was a synthesis of the multi-faceted experience of theatre, which he described as a "living art": "Dramatic art $[\ldots]$ is directed to our eyes, our ears, our understanding — in short to our entire being" ("Elements" 670). Light was integral to Appia's theory: he regarded it as a plastic medium capable of expressing emotional subjectivity and creating the illusion of a three-dimensional and concretised environment, as well as a formal element that equalled and even surpassed the expressive potential of music (Simonson 642). In a summary of Appia's contributions to the New Stagecraft, set and lighting designer Lee Simonson foregrounds the use of light as the most significant, suggesting that light was "the palette and the chisel of scene-designers today," (642). Appia's theories were reified in both the stage settings and critical theory of Bruguière's theatre collaborators, and I believe that they are evident as well in Bruguière's abstract photographs, in which light is rendered plastic and utilised to activate the paper cuts.

László Moholy-Nagy also made a substantial contribution to the discourse about the artistic possibilities of light through his writings and his use of various photographic techniques including the negative-less photogram. Moholy viewed the light-sensitive surface as "the most important element in the photographic process," but felt that its potential had not been properly explored due to the preoccupation with conforming the photographic apparatus to the "traditional laws of perspective" ("Light" 72). The use of light as "a medium of plastic expression," as the title of Moholy's article describes it, was the fundamental revision that artists must put into practice in order to overcome the established codes that limited photography and film. In his own practice, Moholy utilised various techniques to "control" the action of light on the photographic paper — as opposed to "mechanical" reactions through the camera - such as subverting it with lenses and mirrors, and creating distortion by passing it through fluids, crystals, tissue, and other substances of varying opacity and texture ("Light" 73). For Moholy, then, as with Blakeston, the conception of the "new photography" regards light not as an element that reveals the world in its objective state, but instead as a mode of expression that can be sculpted by the artist's hand but which is also capable of overhauling established optical laws and artistic conventions in order to retrain the human sensorium, and the eye in particular, and to open up the individual to new sensory experiences that would in turn lead to new social relations as well. 


\section{"An extraordinary philosophical commentary on sense data": Synaesthetic Photography}

Despite the ethereal and intangible qualities of light, it was frequently utilised in such a way that strengthened the experience of the embodied participant/viewer by activating different senses. In what way, then, does intermediality and the use of light as a creative medium culminate in the synaesthetic experience of the abstract photographs by Francis Bruguière? In order to explore this question, one must first recall Bruguière's working method, which involved long exposure times and multiple exposures on a single plate. As a result of this process, the imperceptibility of the final print was in fact a crucial facet of these photographs. By this, I am referring to the fact that what was recorded on the negative did not exist as a concrete object captured in a specific moment in time, but was instead comprised of various manipulations of light, recorded over numerous exposures. While every analogue photograph contains, in varying degrees, this aspect of "visual blindness," Bruguière's method emphasised and foregrounded this characteristic of the medium. The overall visuality of these images, their end result, would have thus been impossible for Bruguière to accurately predict. With visual perception hampered, the artist would have been obliged to rely on other senses. In this case, the hand of the artist produces what the eye literally cannot see.

The touch of the artist is present in Bruguière's photographs in other ways as well. The sculptural properties of his series "Cut paper abstractions" are evident: the images are literally carved out of paper, and each line and form evokes the hand that produced it [Figs. 1, $3 \&$ 5]. For some critics, this evocation diverted the viewer too far, as correspondence from Bruguière's friend Sadikichi Hartmannn reveals. "I like your inventions, constructions [sic] but feel too much the knife, the cut, the sharp incision [...]" wrote Hartmann in a letter dated January 1931. ${ }^{1}$ Underlying Hartmann's comment is the power of light to transform the mundane substance of paper into an image that stimulates a tactile response in the viewer who can feel "the cut, the sharp incision." The idea that photographs could activate senses other than sight such as Hartmann describes held power for other critics as well. Moholy-Nagy's primary objective was to overhaul the human sensorium as a whole, and he sought to do so by providing the senses with extraordinary perceptual experiences:

It is in the nature of human existence that the senses are insatiable, that they reach out for more new experience every time they take something in. This is the reason for the perpetual need for new modes of creativity. From this point of view creative endeavours are only valid if they produce new, as yet unfamiliar relationships. ("Production-Reproduction" 80)

Sadakichi Hartmann to Francis Bruguière, 31 January 1931. Francis Bruguière Archive, AG52 box 1, folder 32, Center for Creative Photography, University of Arizona, Tucson. 


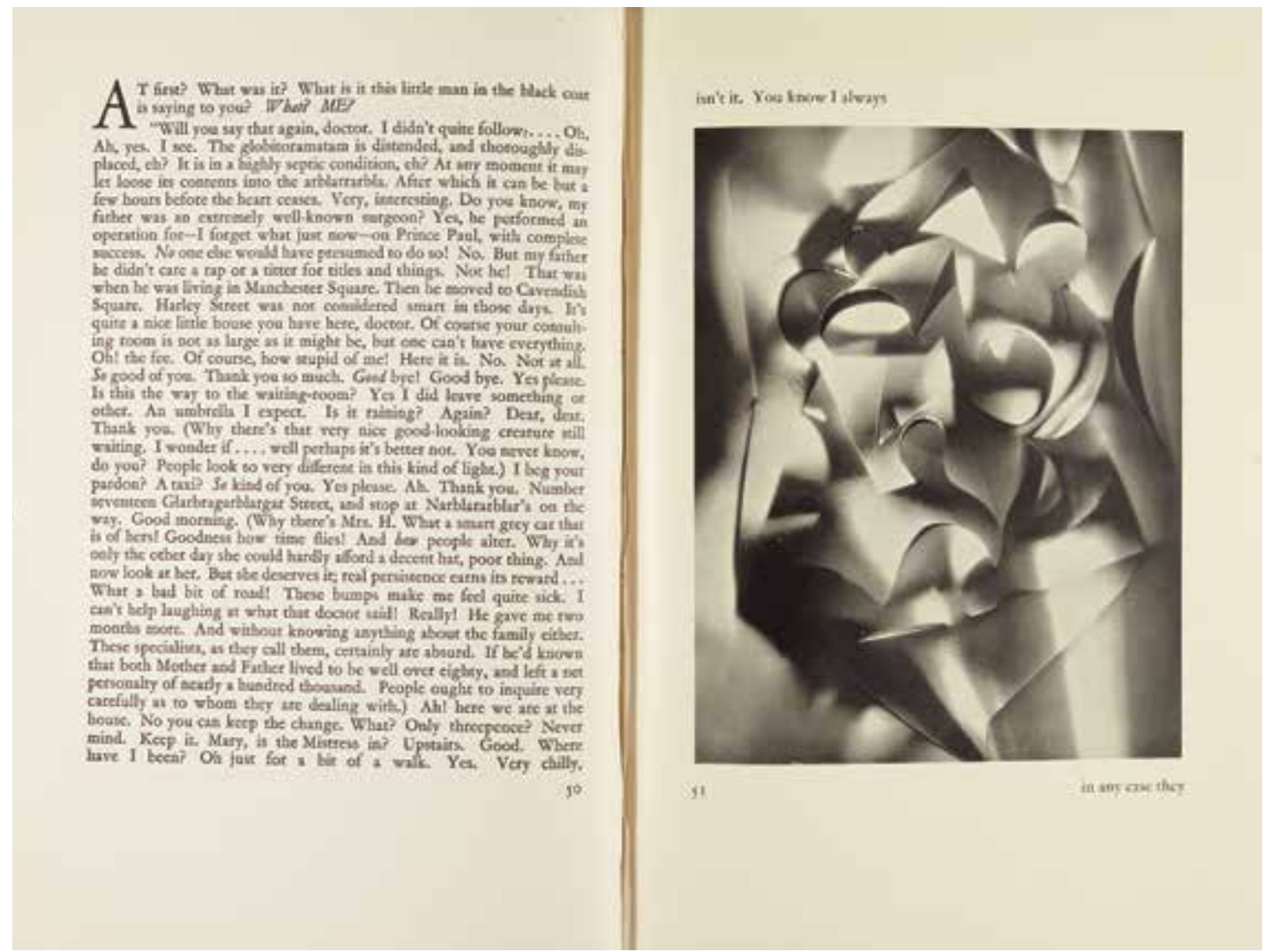

Fig. 3: Francis Bruguière and Lance Sieveking, "Section A. (6) Incredulity: Then Deliberate Inattention." Beyond This Point (London: Duckworth, 1929). Courtesy of the University of St Andrews Library Special Collections (Photo PR6037.I48F29 pgs. 50-51). 


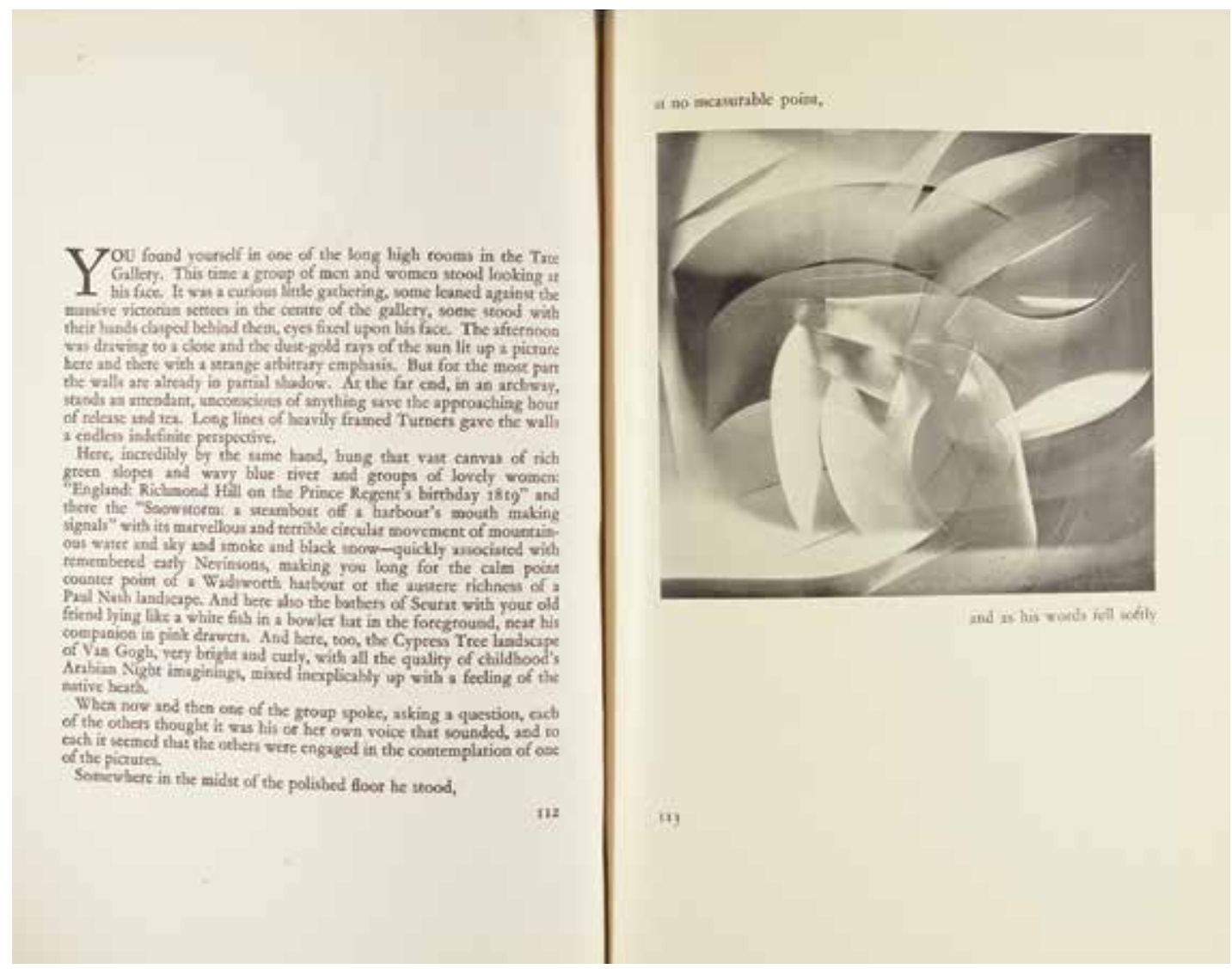

Fig. 4: Francis Bruguière and Lance Sieveking, "Section C. Still Upward, Accumulating Knowledge. Attitudes Towards Social Ruin." Beyond This Point (London: Duckworth, 1929). Courtesy of the University of St Andrews Library Special Collections (Photo PR6037.I48F29 — pgs. 112-113). 

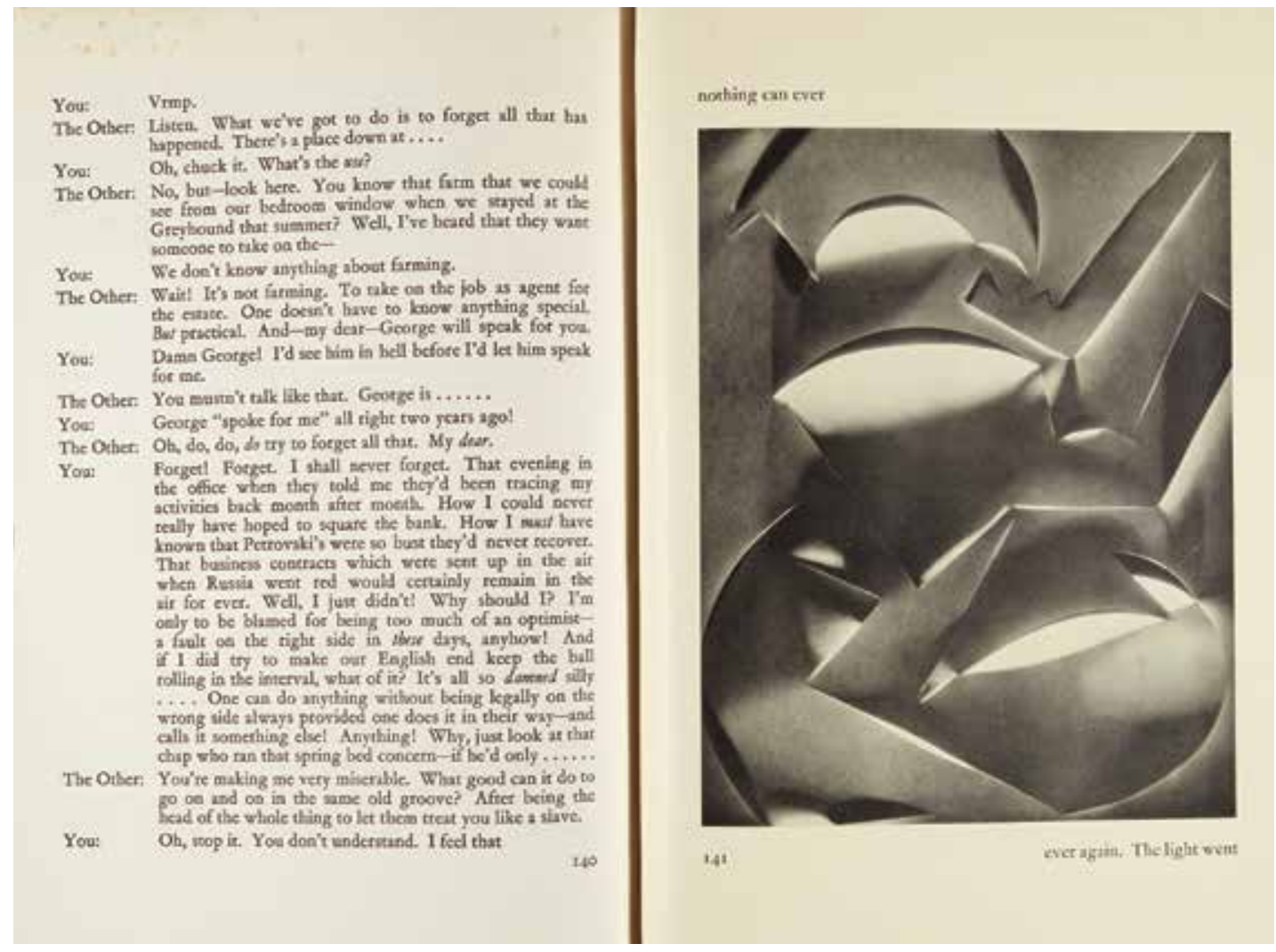

Fig. 5: Francis Bruguière and Lance Sieveking, "Section C. (4) Gloomily on among the Debris." Beyond This Point (London: Duckworth, 1929). Courtesy of the University of St Andrews Library Special Collections (Photo PR6037.I48F29 — pgs. 140-141). 
The crux of Moholy's argument lies in the dichotomy between "reproduction," which utilises new technologies for representational or mimetic ends, and "production," in which such media make visible those aspects of the world not accessible through traditional modes of perception. The latent synaesthetic component in Moholy's statement rests specifically in his accent on the creation of "unfamiliar relationships" between the senses, which can only be generated by "new modes of creativity."

In Bruguière's photographs, the creation of unfamiliar relationships appears in the photographer's use of his materials. Light is crucial to the effectiveness of the "cuts" in accentuating their sharp lines, but of equal importance is light's absence, in the form of dark outlines and empty spaces resulting from shadows. Light and shadow become the key materials of these images, their most basic unit of expression, intangible yet apparently concrete. Also present is Blakeston's notion of "form giving significance to light": by revealing their means of creation as paper and light, thus foregrounding the objective qualities of photography, yet simultaneously rendering the viewer dissatisfied, searching for visual footholds (scale, figurative elements, etc.) which are never fully divulged in the images. These characteristics are even more noticeable in Bruguière's double exposure images, in which two different cut paper abstractions have been exposed on the same plate [Fig. 4]. One image creates a ghostly impression over the other, and the substance of each seems dematerialised, the photograph only secured by the sharp lines of highlight and shadow that seem to suture together the various light effects into a tangible whole. The notion that Bruguière's photographs sought to probe the traditional codes of sensate experience was noted by Blakeston, who mused: "It is strange how few people realise that Francis Bruguière's abstract photographs, in which he made light itself a form, are an extraordinary philosophical commentary on sense data" (“A Note" 24).

Another example of a synaesthetic response to Bruguière's photographs was noted by Harry Alan Potamkin, who identified motion and constructed time as key elements of Bruguière's still photographs. In an article published in the avant-garde literary magazine transition to accompany a portfolio of Bruguière's abstract photographs, Potamkin highlights motion as a critical element of Bruguière's photography, and positions them as a pseudo-cinematic medium, a hybrid of film and photography. "This is not a narrative," wrote Potamkin, "this is an experience kinetic of what the eye knows does not move. [...] Construct these motionless photos in a sequence of forward march cinema is born [...]" ("Francis Brugiere" 81-2). Once again, the concept of montage plays a role in this analysis. The "collision" of images is literal this time, in images that are layered visually and temporally through multiple exposures [Fig. 4], and in which the repeated application of light sources over time combine to create images in which motion is implied, if not enacted [Fig. 3]. These images are, in a sense, structurally akin to cinematic forms, which are created, as Eisenstein points out, by "immobile 
images" from which "the idea (or sensation) of movement arises" through superimposition (49). For Potamkin, Bruguière's artistic practice pointed the way forward for filmmakers and photographers alike: "Photography must look to Bruguière, and cinematography may look to him too. The absolute film. The film of constructed forms. The symbolic film. The film of fluid colours" ("Francis Brugiere" 82). The filmic potential of abstract photographs, and, by extension, the possibility of movement in stillness, is nowhere else expressed so explicitly.

\section{Conclusion}

The interwar era was a period marked by the re-evaluation of different modes of artistic production. Against attempts to stake out a fixed and essential nature for photography, many photographers, theorists and critics sought to transgress the boundaries that confined the medium. In regarding light as a plastic and creative medium, they pushed artistic practice and theory away from the borders defined by objectivity and visuality and into intermedial realms where the anticipated sensory reactions were overturned. Key contemporaneous theories from discourses such as film, theatre, and light art are productive frameworks within which to view abstract photographs. At the same time, contemporary scholarship continues to challenge the primacy of visuality amongst the human sensorium and reassert the role of all the senses in our experience of culture. This "realignment" of the perceptual apparatus, in which the roles of marginalised senses are reconsidered, has profound implications in our understanding of the presumed objectivity and verisimilitude of the photographic medium.

With its ability to depict visual circumstances that are not available to the naked eye, W.J.T. Mitchell describes photography as "[...] a device for translating the unseen or unseeable into something that looks like a picture of something that we could never see" (260). Almost without exception, Bruguière's abstract and figurative photographs depict what is invisible to the naked eye, and which, therefore, cannot be interpreted solely through the frameworks of visuality and objectivity, but instead functioned as catalysts for synaesethetic experience. The tactile effects of these images, along with the long duration of their exposures makes visible temporal qualities of a cinematic nature, while the movement of the light source brings a sense of motion to photographs in which the camera and subject matter remained stationary. The blurred boundaries between media are more likely to stimulate a synaesthetic reaction than media which rely on the hierarchisation of one sense over the others. In transgressing the key photographic tenet of verisimilitude through the application of multiple-exposures and the use of abstract images, Bruguière's photographs are not only aesthetically interesting experiments: they call into question the function of the photographic medium as an objective, transparent and purely visual medium. 


\section{Works Cited}

APPIA, Adolphe. "Actor, Space, Light, Painting." 1919. Adolphe Appia: Texts on Theatre. Ed. Richard C. Beacham. London: Routledge, 1993. 115-16.

"The Elements of a Work of Living Art." 1921. Trans. from French by Rosamond Gilder. Theatre Arts Monthly (August 1932): 667-78.

BARON-COHEN, Simon, and John E. HARRISON. "Synaesthesia: An Introduction." Synaesthesia: Classic and Contemporary Readings. Eds. Simon Baron-Cohen and John E. Harrison. Cambridge, Mass: Blackwell, 1997. 3-16.

BLAKESTON, Oswell. "A Note on the Camera and Philosophy.” film art 10, vol. 4 (Spring 1937): 24.

BROUGHER, Kerry, and Judith ZILCZER. Visual Music: Synaesthesia in Art and Music since 1900. London: Thames \& Hudson, 2005.

BRUGUIÈRE, Francis. "The Camera and the Scene." 1924. Theatre Arts Anthology: A Record and a Prophecy. Eds. Rosamond Gilder, Hermine Rich Isaacs, Robert M. MacGregor, and Edward Reed. New York: Theatre Arts Books, 1950. 400-2.

, and Lancelot de Giberne SIEVEKING. Beyond This Point. London: Duckworth, 1929.

CYTOWIC, Richard E. "Synaesthesia: Phenomenology and Neuropsychology: a Review of Current Knowledge." 1996. Synaesthesia: Classic and Contemporary Readings. Eds. Simon Baron-Cohen and John E. Harrison. Cambridge, Mass: Blackwell, 1997. 17-39.

DI BELLO, Patrizia, and Gabriel KOUREAS. "Other than the Visual: Art, History and the Senses." Art, History and the Senses. Eds. Patrizia Di Bello and Gabriel Koureas. Farnham, UK: Ashgate, 2010. 1-17.

EISENSTEIN, Sergei. “A Dialectic Approach to Film Form.” 1929. Film Form: Essays in Film Theory. 1949. Ed. and trans. from Russian by Jay Leyda. London: Harcourt Brace Jovanovich, 1953. 45-63.

HIGGINS, Dick. "Intermedia." 1966. Leonardo 34, no. 1 (2001): 49. doi:10.2307/1576984.

JACOBS, Lewis, ed. The Compound Cinema: The Film Writings of Harry Alan Potamkin. New York: Teachers College Press, 1977.

JÄGER, Gottfried, ed. The art of abstract photography. Stuttgart: Arnoldsche, 2002.

MCCAULEY, Anne. "Francis Bruguière and Lance Sieveking's Beyond This Point (1929): An Experiment in Abstract Photography, Synaesthesia, and the Cinematic Book." More Than One: Photographs in Sequence. Ed. Joel Smith. New Haven: Princeton University Press, 2008. 47-65.

MERCURIUS [Oswell BLAKESTON]. "Light: The Photography of Francis Bruguière." The Architectural Review 65 (January 1930): 39.

MITCHELL, W. J. T. “There Are No Visual Media.” Journal of Visual Culture 4, no. 2 (2005): 257-66.

MOHOLY-NAGY, László. "Light: A Medium of Plastic Expression.” 1922. Photographers on Photography. Ed. Nathan Lyons. Englewood Cliffs, NJ: Prentice-Hall, 1966. 72-3.

"Production-Reproduction." 1922. Photography in the Modern Era: European Documents and Critical Writings, 1913-1940. Ed. Christopher Phillips. New York: The Metropolitan Museum of Art/Aperture, 1989. 79-82. 
POTAMKIN, Harry Alan. "The Compound Cinema." 1929. In Jacobs, The Compound Cinema. 5-8. "Francis Brugiere [sic]: Photo." transition 18 (November 1929): 81-2.

"Phases of Cinema Unity: I." 1929. In Jacobs, The Compound Cinema. 14-20.

"Phases of Cinema Unity: II." 1929. In Jacobs, The Compound Cinema. 21-28.

"Phases of Cinema Unity: III." In Jacobs, The Compound Cinema. 1930. 29-37.

"Tendencies in the Cinema." 1930. In Jacobs, The Compound Cinema. 43-46.

REXER, Lyle. The Edge of Vision: The Rise of Abstraction in Photography. New York: Aperture, 2009.

SIMONSON, Lee. “Appia's Contribution to the Modern Stage.” Theatre Arts Monthly (August 1932): 631-644.

STEIN, Donna. Thomas Wilfred: Lumia; A Retrospective Exhibition. Washington: Corcoran Gallery of Art, 1971.

STRAND, Paul. "Photography." 1917. In Photographers on Photography: A Critical Anthology. Englewood Cliffs, N.J: Prentice-Hall, 1966. 136-37.

WITKOVSKY, Matthew. "Another History: On Photography and Abstraction.” Artforum International 48, no. 7 (March 2010): 213-21.

ZILCZER, Judith. "'Color Music': Synaesthesia and Nineteenth-Century Sources for Abstract Art." Artibus et Historiae 8, no. 16 (1987): 101-26.

\section{List OF ILLUSTRATIONS}

Fig. 1 Francis Bruguière and Lance Sieveking, "Title Page," Beyond This Point (London: Duckworth, 1929). Courtesy of the University of St Andrews Library Special Collections (Photo PR6037.I48F29 - pgs. 4-5).

Fig. 2 Francis Bruguière and Lance Sieveking, "Section A. Humanity: Up He Goes. Attitudes towards the near approach of death." Beyond This Point (London: Duckworth, 1929). Courtesy of the University of St Andrews Library Special Collections (Photo PR6037.I48F29 - pgs. 12-13).

Fig. 3 Francis Bruguière and Lance Sieveking, "Section A. (6) Incredulity: Then Deliberate Inattention." Beyond This Point (London: Duckworth, 1929). Courtesy of the University of St Andrews Library Special Collections (Photo PR6037.I48F29 - pgs. 50-51).

Fig. 4 Francis Bruguière and Lance Sieveking, "Section C. Still Upward, Accumulating Knowledge. Attitudes Towards Social Ruin." Beyond This Point (London: Duckworth, 1929). Courtesy of the University of St Andrews Library Special Collections (Photo PR6037.I48F29 - pgs. 112-113).

Fig. 5 Francis Bruguière and Lance Sieveking, "Section C. (4) Gloomily on among the Debris." Beyond This Point (London: Duckworth, 1929). Courtesy of the University of St Andrews Library Special Collections (Photo PR6037.I48F29 - pgs. 140-141). 